\title{
Selective exclusion: the digital divide in the context of indigenous knowledge systems in South Africa
}

\author{
H. Lotriet * \\ Department of Informatics \\ University of Pretoria \\ Pretoria, South Africa \\ hugo.lotriet@up.ac.za
}

\section{Matthee}

Department of Informatics

University of Pretoria

Pretoria, South Africa

machdel.matthee@up.ac.za

\author{
F. Mazanderani \\ Oxford Internet Institute \\ University of Oxford \\ Oxford, United Kingdom \\ fadhila.haerimazanderani@oii.ox.ac.uk
}

This article provides an alternative view to questions of technological inclusion and exclusion in sub-Saharan Africa via an analysis of the South African governmental discourse on indigenous knowledge systems (IKS). The concept of 'selective exclusion' (SE) is developed in relation to the digital divide, highlighting that technology is not always perceived as neutral or universally beneficial, but rather is negotiated in relation to specific socio-political contexts and alternative systems of knowledge. The concept of SE highlights the following: (a) 'Western' rationality and technology can be perceived as threats to indigenous identity and knowledge and as a result treated circumspectly; (b) nevertheless the 'Western' domain is seen as promising economic benefits, which need to be accessed; (c) therefore, the 'Western' domain and its associated technologies are selectively excluded; (d) the existence of a digital divide is not necessarily seen as negative as it offers protection against globalisation; and (e) the agency of indigenous individuals and communities is considered central and the ability to appropriate technology in relation to this is stressed.

Key words: Digital divide, indigenous knowledge systems, selective exclusion, Africa, South Africa, ICT

Received 20 March 2009; accepted March 2009

\section{Contents}


1. Introduction

2. Digital divide and indigenous knowledge systems

2.1 Digital divide and the rhetoric of marginalisation

2.2 Role of government discourse

2.3 South African context

2.4 IKS and the digital divide

3. Design and method

4. From digital divide to 'selective exclusion 4.1 Overview of the IKS discourse

4.2 Themes from speeches and the policy document $(2001-2005)$

4.3 Towards the institutionalisation of IKS (2006 - 2008)

4.4 Correspondence of findings to discourses on IKS in literature

4.5 Selective exclusion' view of technology

4.6 ICT applications in the context of IKS elsewhere in the world

5. Discussion

6. Conclusion

7. References

\section{Introduction}

At its simplest the 'digital divide' is defined as 'the gap separating those individuals who have access to new forms of information technology from those who do not' (Gunkel 2003:499). Although pleasingly alliterative, its application, both in the popular imagination and academic research, has been much criticised for its techno-centricity and rhetorical simplification (Couldry 2003; Gunkel 2003; Mansell 2001; Murdock and Golding 2004; Roode, Speight, Pollock and Webber 2004; Van Dijk and Hacker 2003; Warschauer 2002). As a result it is now widely accepted that the concept of the digital divide is as variable and multifaceted as the technology whose distribution it aims to equalise. Despite, or perhaps because of this, it continues to be a popular designation for studies focusing on different dimensions of the unequal distribution of information and communication technologies (ICT). Consequently there is a large and growing body of work within the digital divide paradigm that is based on a nuanced appreciation for the relevance of context on a micro individual as well as macro societal level. This research contributes to this discourse by situating a grounded analysis of the South African governmental discourse on indigenous knowledge systems (IKS) in relation to the digital divide.

Issues pertaining to ICT and development are closely entwined. With the belief in the existence of a digital divide it is unsurprising, therefore, that a number of the criticisms levelled against the digital divide concept are also prevalent in the literature regarding ICT for development. One such criticism, which this research focused on, is that the discourse marginalises the very people it aims to empower by privileging the value of technical 'western' knowledge at the expense of local capability (Burkett 2000; Schech 2002; Wilson 2002). Lack of access to ICT is conflated with lack of information and, by association, knowledge, resulting in the creation of the category of 'information poverty'. It is partly in response to this that indigenous or local knowledge has received considerable attention as a possible escape route from the perceived impasse that has been reached in many developmental initiatives (Briggs 2005:99). Proponents hope that via an appreciation for the salience of IKS the agency and inherent worth of the people who are the 'object' of development will be brought to the fore. In relation to the digital divide debate, this emphasis on IKS offers an opportunity for a deeper investigation into the 'have-nots', accentuating what they 'have' versus what they lack. Via a qualitative analysis of the South African governmental discourse on IKS, this research developed the concept of 'selective exclusion', offering an alternative view on the appropriation of ICT in an African context. In doing so the importance of taking a historically situated approach to ICT and development is stressed. 
Although the scope of the analysis is limited to a high-level discourse in South African governmental circles, it is illustrative of how discussions on the digital divide need to be cognisant of a local socio-political context which does not necessarily treat 'western' technology and rationality as something desirable in and of itself.

Firstly a brief overview of research on the digital divide as it relates to this research is presented, followed by an outline of the methodological approach. The core of the article, however, is a discussion on the empirical findings of an analysis of the governmental discourse and associated policy document on IKS. This is based on a thematic analysis of speeches made by South African government officials over a period of seven years and the official policy document of the South African government on IKS (South Africa. Department of Science and Technology 2004). A section follows that highlights aspects of IKS discourses in literature that relate to the findings of the analysis. The development of the concept of 'selective exclusion' is then discussed, followed by an analysis of what some of the potential implications of a 'selectively exclusionary' approach might be for ICT and development in South Africa.

\section{Digital divide and indigenous knowledge systems}

\subsection{Digital divide and the rhetoric of marginalisation}

Since its inception the concept of the digital divide has been both popular and contested. It has been applied to and recognised as having relevance across a diverse area of concerns ranging from education, economic and political participation, heath care and social participation (DiMaggio and Hargittai 2001; Gurstein 2003; Van Dijk 2005). The concept of the digital divide, however, implies a binary differential; you are either a 'have' or a 'havenot', when in reality the situation is more nuanced. The concept also implies an inherent value judgement, with the technological 'haves' occupying a privileged position that all should aspire to. Its rhetorical form conceals the existence of numerous 'divides', not all of which are externally enforced. Some of these 'divides' can be voluntary or selective rather than simply being a negative consequence of lack of access to resources.

Numerous alternatives to the digital divide construct have been posited. Examples include Roode et al.'s (2004) 'socio-techno divide', Warschauer's (2002) 'technology for social inclusion', Gurstein's (2003) community informatics strategies and Cushman and Klecun ' s (2005:2) 'digital exclusion' to mention but a few. While these approaches differ, they share a number of common features upon which this research was premised. Firstly it was assumed that the adoption and use of technology is potentially benevolent in terms of socio-economic development, but that there needs to be a strong focus on the recipients of technology as active social role-players. People of all socio-economic tiers can never simply be treated as passive recipients of technical largesse, and equating improved access to technology with improved lives is a grossly over-simplified view. Based on this, a grass roots approach to structuring the use of technology is frequently advocated with a stress on people's selfassessed needs and behaviour rather than superimposed expectations. It is essential in such a discussion to remember that people do not exist in a vacuum; that their cultural and historic differences need not only to be taken into account in abstract but integrated into the development process. To facilitate this it is important to develop a deeper understanding of how different role players involved in development initiatives view ICT, with minimal imposition from pre-existing researcher bias. While research has shown how access or lack of access is stratified by factors such as age, education, location, income, employment and gender, less work has been done on the active decision-making process carried out by various stakeholders as they negotiate with technology. One group of pertinent stakeholders 
(although by no means the only or most important one) are government representatives and it is the public discourse of this group that the empirical portion of this research analysed.

\subsection{Role of government discourse}

A discourse is a 'particular system of making sense of the social world out of which commonly accepted actions emerge' (Wilson 2002). By analysing the South African governmental discourse on IKS, it was hoped that some of the assumptions and perceptions surrounding the relationship between ICT and IKS could be unpacked, contributing towards a deeper understanding of what constitutes a non-binary digital divide. While governmental discourse does not contain a complete or even partially complete reflection of the environmental factors that influence issues of technology diffusion (Wejnert 2002), the government has an important role to play in the initiation of ICT projects as well as contributing to a suitable regulatory environment for ICT to flourish. In addition, a significant portion of ICT research in Africa has a developmental focus and is closely linked to the governmental sector, which often drives development efforts. Although the role of governments and high level players can be viewed as both potentially negative (Gurstein 2003; Warschauer 2003) and potentially positive (Roode et al. 2004) that they play a role of some kind is not in doubt.

The implications of policy on the digital divide have been discussed in some detail in relation to the European Union and the United States (Stewart, Gil-Egui, Tian and Innes Pileggi 2006) as well as to developing countries (Dasgupta, Lall and Wheeler 2005), highlighting the role that policy can and does play. When a discourse becomes prominent in government circles it is often translated into policy and regulation (as has been the case with IKS) and can be influential in a number of ways, not least of which is in the allocation of funding and initiation of projects. Green (2008:49) emphasises the need for research that focuses specifically on South African IKS policy makers (i.e. government) and their underlying assumptions. This relates partly to the fact that very few governments play the role of advocate for 'knowledge diversity' and the IKS policy document produced by the South African government is considered the most advanced of its kind in the world, thus making the role and position of the South African government fairly unique (Green 2007:134).

This research focused exclusively on a specific South African governmental discourse which cannot be assumed to be transposable to other African countries. South Africa is in itself made up of a diverse cultural, ethnic and linguistic population and the discourse analysed is not meant to reflect a unified perspective. The scarcity of research of this nature on subSaharan Africa is considered validation enough to have focused on South Africa but, in addition to this, there was added significance on selecting South Africa, which is discussed briefly in the following section.

\subsection{South African context}

South Africa is a middle income developing country with one of the most unequal distributions of wealth in the world. Many indicators, however, suggest that it is in a good position to benefit from technological development (Bridges 2001; UNDP 2000; UNDP 2004), the potential for which is increased when countries have acquired a critical income or absorptive capacity level (Soete 1985:411). At the same time, the digital divide is a 'term that could have been coined for South Africa' (Makhaya and Roberts 2003:47). Hence while many elements are in place for South Africa to leverage ICT for development purposes, the situation is more complicated than often assumed in the technological 'leapfrogging' model.

The country emerged from a political heritage that had regarded information and education as both a gateway to empowerment and an instrument of oppression (Postma 2001). There is 
a strong desire to increase African identity which has historically been lacking in regional information services and which created a pervasive sense of dissatisfaction and a suspicious attitude towards these services (Nassimbeni 1990:167). It is felt that 'western' models of Internet use and broader ICT adoption are not always aligned with local cultural values as can be seen in the educational environment where individual-focused learning is accepted with difficulty and 'individual excellence is still regarded as a Western preference' (Postma 2001:234).This is not to suggest that South Africa is a fictitious archetype of pan-African post-colonial suspicion, but rather that the desire frequently expressed in South Africa for the development and appreciation of a sense of Africaness is not unique. In addition, South Africa is an economically and politically prominent country in Africa, an example of which is its leadership role in NEPAD (NEPAD 2001). In relation to indigenous knowledge, South Africa has taken significant steps towards institutionalising IKS, through policy and research (South Africa. Department of Science and Technology 2004), making it one of the priority focus areas of the South African National Research Foundation (National Research Foundation 2006).

\subsection{IKS and the digital divide}

In analysing the IKS discourse, the intention was not to uncover an utopian development ideal in opposition to the view that access to ICT is a beneficial development imperative. It has to be recognised from the outset that the IKS discourse is embedded within its own rhetorical paradigm, but it is a discourse that can provide an enlightening contrast to the more traditional 'ICT for development' one. As such its selection is not only based on its relevance to the broader ICT for development discourse but also as illustrative of an alternative to the pervasive information rich versus poor dichotomy (Burkett 2000; Schech 2002; Wilson 2002). IKS is one example of a more user-centred approach to development, stressing that 'communication is not just about delivering information to the poor and oppressed; it can also be about transmitting information and knowledge from these groups to a wider audience' (Heeks 2002:3). The adoption of 'the language of IK' (Briggs and Sharp 2004:667) by influential institutions such as the World Bank (1998) is an indicator of the way in which international bodies involved in development are engaging with IKS. The discourse on IKS, therefore, has relevance in Africa, not only because of its numerous developmental challenges but also because it seems to offer an alternative to Africans being treated as passive recipients of externally provided technological innovation.

For the purpose of this research the definition of IK used in the South African government policy document on IKS was adopted:

'Indigenous knowledge (IK) is generally used synonymously with traditional and local knowledge to differentiate the knowledge developed by and within distinctive indigenous communities from the international knowledge system generated through universities, government research centres and private industry, sometimes incorrectly called the Western knowledge system' (South Africa. Department of Science and Technology 2004:10).

Based on this definition, it is difficult to delineate what is encapsulated under the IKS rubric, which by definition is intended to be heterogeneous and local. Within the policy document there is, however, a strong emphasis on cultural goods as well as traditional medicine and agricultural practices. The purpose of the analysis is not to explicate or critique IKS per se but rather to generate a better understanding of explicit and implicit views on technology expressed in the IKS discourse that relate to the digital divide and ICT for development debate. 


\section{Design and method}

The principles and guiding philosophy of grounded theory has been used as the basis for a significant number of studies in Information Systems (Hughes and Jones 2003) and this research used the version advocated by Strauss and Corbin (1998). This approach was deemed suitable due to a number of reasons, not least of which was the exploratory nature of the research. In addition, it was well aligned with the intention to minimise the imposition of preconceived notions and expectations on the empirical portion of the study. [It should be noted that, even though a significant body of research on the wider concept of IKS exists, multiple possibilities of theorising exist (Green 2008:49) - this would be a further argument against imposing preconceived notions on the data.] The founding assumptions of grounded theory such as the close interaction between researcher and data, the emphasis on temporally and spatially bounded findings and its collaborative and discursive nature were also felt to be appropriate.

As the aim of the research was to analyse government discourse pertaining to IKS in the context of the digital divide, a search was carried out on the official repository of South African government speeches by senior figures in the Department of Science and Technology (South African Government 2007). All speeches that referenced IKS substantively (i.e. made more than a fleeting reference to the concept or another document) were analysed. These speeches were presented by South African government officials over the period 2001 to 2008. In addition, the official IKS policy document released by government (South Africa. Department of Science and Technology 2004) and some press releases from the Department of Science and Technology were analysed. Although South Africa has 11 official languages, the speeches in the repository were all in English and no need for translation was necessary. The speeches were delivered to diverse audiences, ranging from South African government representatives and African peers to international bodies and diverse IKS holders and practitioners. The complete list of speeches that were analysed can be found in Appendix A.

The open coding portion of the research was conducted independently in order to identify as many potential dimensions and meanings in the data as possible. This was followed by the axial coding which was performed collaboratively during which categories and subcategories were linked through the consideration of their highlighted properties and dimensions. Finally, during selective coding, the emerging theory was refined and integrated through the discovery of the 'main theme' or 'core category' that related to all categories and could be used as an integrating concept. This final stage also allowed for the refinement of the analysis in terms of consistency, logic and completeness. Although a detailed grounded analysis was made of the speeches and the IKS policy document, only the main findings that relate to the discussion of the location of ICT within this discourse are presented below.

top

\section{From digital divide to 'selective exclusion}

\subsection{Overview of the IKS discourse}

The speeches and policy document analysed were selected due to their specific focus on IKS, but their discourse was embedded within a much wider socio-political narrative. While it is not the aim of this article to provide a detailed description of this narrative, it is also not possible to isolate the categories that relate specifically to ICT from their broader context, without stripping them of meaning. To provide the appropriate background, a brief summary of the IKS discourse is presented prior to a description of the development of the concept of 'selective exclusion'. The speeches from 2006 onwards differ from the earlier documents in 
that they show a definitive move towards practical measures and implementation of policies developed in earlier work. The overview of the themes and sub-themes that were identified during the analysis are discussed according to these groupings.

\subsection{Themes from speeches and the policy document (2001-2005)}

The overarching theme that emerged from the analysis was the desire and intention to affirm an African identity via IKS. The multiplicity of what constitutes an African identity is recognised in the discourse and yet the idea of an African identity is often referenced as a unitary constant. While the opportunity and potential of IKS is highlighted repeatedly the discourse is also laced with and defined in relation to a threat. The threat is perceived as coming both from the 'international' (as it is referred to in the documents analysed) economic rationality as well as the local, South African, history of oppression. While the opportunities offered by 'international' resources and knowledge are recognised they are not privileged above the desire to promote African emancipation, unity and heritage, a drive which is often grouped under the direction of the African renaissance. It is within this context that the value of IKS is stressed, not as an alternative for 'international' technology but rather as the foundation for initiatives that may or may not include the leveraging of external resources such as biotechnology or ICT. IKS is seen as being representative of African thinking and processes, as being human-centred and arising from communities rather than individuals, where its roots are located in the lives, beliefs and folklore of the indigenous people. Through the agency of IKS (although where this agency originates from is often not clear), benefits will be derived such as creativity, self-discovery and emancipation. The discourse is imbibed with a sense of hope that the institutionalisation of IKS will result in locally relevant action, create a sense of community, redress imbalanced legacies, and improve lives, dignity and equality. Three main points that emerged from the analysis as key to the process of insitutionalisation are:

The commodification of IKS, which will result in economic benefits to IKS holders (presented in the discourse as predominantly being the unemployed, women and/or black people and communities).

- The recognition of IKS as a scientifically valid discipline in terms of its epistemology and ontology. This will allow IKS to take its rightful place in science and technology education, thus granting the knowledge grounded in the African tradition scientific validity and status.

- Partnerships and co-operation founded on IKS will add value to world debates where IKS will be perceived as being synergistic to 'international knowledge systems' and where IKS holders and communities will benefit from relationships with the private sector, industry and government.

\subsection{Towards the institutionalisation of IKS (2006-2008)}

Although no new themes emerged from the analysis of the speeches delivered during this period, what sets this period apart are the deliberate attempts of government to institutionalise IKS. During this period the National Office on IKS (NIKSO) and the ministerial IKS Advisory Committee were established. The minister of the Department of Science and Technology announced a 'Ten Year Plan on Innovation' during his address at the induction of the IKS Advisory Committee (Mangena 2008) and, as part of this ten-year plan, several strategies and actions were proposed, some of which are discussed below.

Raising public awareness of IKS was seen as an imperative and various strategies such as the hosting of competitions and expos were seen as a mechanism for achieving this (of which the first one took place in August 2008). The hope is that through these initiatives, civil society 
will develop an appreciation of the commercial value of IKS products and how they can leverage the opportunities offered by IKS. Another important aspect relating to the commodification of IKS, is the work being done by government on the Intellectual Property Amendment Bill in order to protect IKS and its owners (South African Government 2008), with amendments to the Patent Act being approved affirming the ownership of IKS (Mangena 2006).

The drive towards the recognition of IKS as scientifically valid discipline as well as the integration of IKS with other knowledge systems is expressed as being high on the agenda and it is hoped that this could be achieved through the introduction of a degree in IKS in higher education institutions (HEI). Such a degree is currently being reviewed by the SA Qualifications Authority (SAQA) (South African Government 2008). In addition, research chairs on IKS will be established at HEI (of which the first one on traditional medicine is based at the Nelson Mandela School of Medicine).

Analysis of the documents from both time periods shows that in order to realise these initiatives promoting IKS and consequently the benefits from it, some external (nonindigenous) support functions need to be in place in order to ensure that IKS is recorded, documented and disseminated. It is in this category that ICT is placed. Already, a national audit on IKS databases hosted by different institutions was completed, laying the ground work for a national IKS database (Mangena 2007b). The establishment of a pilot IKS centre at the University of KwaZulu Natal has as its main purpose the recording, codification and dissemination of IKS (Mangena 2007a). It is also foreseen that computers will be made available to the public in disadvantaged communities to enhance knowledge sharing (South African Government 2008). It is clear from the abovementioned initiatives that ICT is seen as a very valuable resource and support function to IKS. It is not, however, viewed as politically neutral but rather as something that needs to be negotiated with and managed. Rather than the digital divide being seen as a question of 'bridging a gap' between people who 'have' versus those who 'have not', the IKS discourse shifts the impetus from universal inclusion to selective exclusion.

\subsection{Correspondence of findings to discourses on IKS in literature}

An examination of literature on IKS revealed a number of discourses. These focus on IKS as culturally embedded behaviour (Fischer 2005:745); IKS in the context of 'local' vs. 'global' (Green 2008:50; Higgs 2005) and IKS in Africa and South Africa (Green 2008).

Much of what is published situates the concept of IKS within the post-colonialist domain where 'western' knowledge and knowledge production processes are seen as 'hegemonous' and the 'universality' of knowledge is seen as an entrenchment of unequal power relationships in society (Higgs 2005:1). In this context, commitment to indigenous knowledge is seen as the way to 'restore dignity to African Knowledge' (Green 2008:49) and even to address the weaknesses of 'western' knowledge (Du Toit 2005:68). This particular position on IKS is usually linked to arguments for a developmental focus as part of the IKS agenda (Green 2007:131; Ngulube and Lwoga 2007:121; Sen 2005:376), which in the South African context relates to the socio-political benefits of intellectual property rights for the disadvantaged sections of society and empowerment projects (Loubser 2005). Recognition of the validity of these systems in order to realise the developmental aims requires managing of the knowledge through documentation and other processes (Sen 2005). 'Validation' may have interesting implications in terms of ICT usage - Tjiek (2006:124) reports on an instance in Indonesia where (due to the cultural factors) digitised versions of IK has more status and 'appeal' among locals than the same knowledge in a more 'traditional' format would have.

The question of how to manage indigenous knowledge has received some attention in the 
literature, with authors advocating both the use of established knowledge management models such as those developed by Nonaka, Toyama and Konno (Ngulube and Lwoga 2007:121), arguing that knowledge management practices are essentially 'universal', as well as more nuanced approaches to the creation of IK 'assemblages' (Watson and Huntington 2008:259).

From a non-socio-political perspective researchers deconstructing concepts related to 'knowledge' tend to point out the problematic nature of separating 'western' and 'indigenous' knowledge (Fischer 2005:737; Green 2007:135). In this regard it is interesting that researchers tend to highlight the similarities rather than differences between scientific ('western') and indigenous ('African') knowledge. Some of these similarities include: (a) the persistent presence of a cultural influence (Wallner 2005: 47); (b) that all knowledge is essentially local, with only the networks of actors aligned to certain local 'knowledges' being more wide-spread and thus creating an 'illusion of universality' (Higgs 2005:7); (c) the limited differences in instantiations of applied 'scientific' and 'indigenous' knowledge in terms of its richness and complexity and in both instances the underlying knowledge system serves mainly as a 'legitimating device' (Fischer 2005:743) (d) that portrayal of either knowledge system as bounded is problematic (there are long histories of mutual interactions between knowledge systems) (Kargbo 2005:200; Watson and Huntington 2008:275); (e) that neither system is homogenous (within any geographical or temporally selected boundary) (Green 2007:135); and (f) the fluid nature of these systems (Green 2007:136; Kargbo 2005:200).

\section{5 'Selective exclusion' view of technology}

Selective exclusion is indicative of the rejection of people in 'developing' or 'less developed' countries of the mantle of information poverty. It represents a disentangling of knowledge from information and information from information technology. It echoes the criticisms that have been levelled against the 'modernisation' slant of a great deal of ICT for development literature and the binary differential implied in the digital divide debate. Instead of being portrayed as a universal good, 'international' rationality and technology, in the selective exclusion view that emerged from the IKS discourse, are seen as both an opportunity and a threat. There is a strong feeling that not all 'international' systems are aligned with 'local' prerogatives as expressed by Ben Ngubane, the then South African Minister of Arts, Culture, Science and Technology, in a speech on IKS in 2001, in relation to intellectual property: ' there is a concern that Intellectual Property Rights System encourages the appropriation of traditional knowledge for commercial use without a fair sharing of benefits with the holders of this knowledge' (Ngubane 2001). This emphasis on the need to protect local knowledge and knowledge holders is common across the speeches and is re-iterated numerous times in the policy document. Sometimes the threat is seen as coming from external systems and processes or from the historic 'hostile socio-political environment characteristic of colonialism and apartheid' (South Africa. Department of Science and Technology 2004:10). 'Western' rationality and systems are not, however, treated as universally negative and there is a strong recognition of the promise of economic benefits, which need to be accessed for the advantage of previously marginalised groups. Therefore, it is suggested that systems of technology can be selectively excluded from a partnership between local and international knowledge systems. The emphasis being on the appropriation of technology in order to harness the potential of local knowledge as expressed in this extract: 'The challenge before us is to bring about synergy in our actions in terms of indigenous and western knowledge, and other knowledge systems, so that knowledge generation and utilisation benefits all segments of our society, without causing disparities or lopsided development' (Mangena 2004).

In this context, the existence of a divide offers a measure of protection against globalisation and there is not necessarily a need for the divide to be fully bridged. Rather than the 
appropriation of ICT being paramount, the need to protect and promote local systems is the overriding theme: 'For indigenous knowledge to survive on its own terms, the social and economic context in which it develops and continues to develop has to be nurtured, maintained and protected' (Mangena 2004). Selective exclusion as espoused in the discourse allows for both the protection and promotion of IKS to assist South Africa in producing 'its own knowledge agenda for its own development' (Mangena 2008). Its essence is perhaps best summed up by the phrase 'we need to dream and realise new visions in the old ways' (Sonjica 2003), articulated by Buyelwa Patience Sonjica who was Deputy Minister of Arts, Culture, Science and Technology at the time.

In terms of ICT contributing to the realisation of these developmental benefits while being 'selectively exclusive', there are some challenges that need to be considered. These include: (a) balancing effectiveness of resource use against local capacity building; (b) risk of disempowerment of local custodians through global knowledge dissemination; and (c) the contextual 'dislocation' of knowledge leading to reduced significance of such knowledge (Augusto 2008:214).

\subsection{ICT applications in the context of IKS elsewhere in the world}

Various practical initiatives elsewhere in the world have been reported on. Although it is outside of the scope of this article, interested readers are referred to reports on work done in India such as the Traditional Knowledge Digital Library (Chikonzo 2006:136; Green 2008:50; Sen 2005:379), biodiversity knowledge among tribes in the Terai region (Sen 2005:379) and the National Institute of Rural Development in Hyderabad (Tella 2007). In Australia, initiatives in preserving Aboriginal knowledge include Aboriginal Voice - a forum involving Aborigines in discussions on the use of ICT to preserve their IKS - and Metisradio that contributes to the preservation of the Aboriginal cultural heritage (Chikonzo 2006:135). In Africa, a pilot project at a university library in Sudan has been reported on (Sen and Khashmelmous 2006).

Although a detailed discussion of practical ICT challenges is outside the scope of this article, the following challenges are reported in literature (Chikonzo 2006:137-138; Kargbo 2005:204; Mehta and Kalra 2006; Sen 2005; Sen and Khashmelmous 2006;): (a) Availability of suitable technologies; (b) scalability; (c) data structures and data complexity; (d) metadata standards and application of metadata to large data sets; (e) security; (f) customisability and flexibility; (g), complexity; (h) establishment of organisations, structures (typically libraries) and networks to deal with the collation and preservation of IKS; (i) financing the establishment and maintenance of technologies; and (j) cultural acceptance and diffusion of technology.

\section{Discussion}

The analysis of the IKS discourse presented above reveals what has been dubbed a 'selective exclusion' view of ICT that emerged in relationship to IKS, but what are the implications of this perspective and what does it contribute to the digital divide debate? In one sense it suggests a sophisticated socially sensitive understanding of ICT in relation to local knowledge, one in which IKS and ICT need to be aligned in order to maximise benefits for local and international stakeholders. What is more problematic, however, is trying to understand how, once one steps away from the rhetorical appeal of IKS, this would work in practice. Roode et al. (2004) quote Kvasny and Truex (2001:399) who in their analysis of the statements made by US government officials found a recurrent technological determinist view in which technology was 'treated as this magical force that will erase centuries of 
discrimination and inequality'. On the other hand, a 'selective exclusionist view' in the context of IKS would primarily view ICT as enabler of the extension of local African practices beyond its own boundaries (Higgs 2005:7). Such ICT use would enable local communities not only as users but as contributors (Sen 2005:375). The authors would expect ICT projects and initiatives supportive of these aims to be embraced and supported by government.

The emphasis on IKS as the foundation for an Afro-centric development model is in many ways an evolution of and improvement on more techno-centric approaches. While this represents a positive shift away from the rhetoric of the 'haves' and 'have-nots', it needs to be wary of instituting a false duality that separates African indigenous knowledge from 'international' systems and expertise. Although understandable, when viewed in relation to the socio-political history of South Africa, it contains within it a danger that is both subtle and insidious. As much as the discourse demonstrates an appreciation of the advances that have been made in the ICT for development literature, and challenges the construct of information poverty, certain important issues have been omitted or are brushed over. The first of these, as has already been alluded to, is the artificial creation of a North-South divide, where in reality the international and intra-national distinction between those who have access to ICTs is much more blurred (Burkett 2000). The second and related point is that neither IKS nor the international domain could be considered as monolithic entities. The parameters of 'have' and 'have not' may have been redrawn but there still is the risk of a binary opposition, of an 'us' versus 'them' polemic.

The belief in the agency of indigenous knowledge holders to choose their level of involvement with ICT is creditworthy, but it is also an oversimplification of a complex phenomenon. The ability to separate technology that will promote IKS from that which threatens is not only practically infeasible, but also belies the process of technological innovation, which is rarely a linear centrally controlled event. An example of this complexity can be seen in the adoption of mobile telephony in South Africa. It would appear on the surface that mobile telephony belongs to the 'international' paradigm of globalisation and yet it has not only been enthusiastically received into the South African market but has also been used in novel 'South African' ways (Reck and Wood 2003; Vodafone 2005). This is illustrative not only of how globalisation has a much more fragmentary influence on culture than is often assumed (Appadurai 1990), but also of how different uses and adaptations of technology emerge over time (Orlikowski 2000). The only way that ICT processes, products and artefacts that embrace and represent African ideas or values can be developed is via exposure and access to technology, the consequences of which will not always be visible beforehand. If ICT is to become part of the indigenous research agenda, being researched by Africans in terms of African ontologies and epistemologies, there needs to be symmetry in the way IKS and ICT are treated, even if that symmetry does not equate to equality.

\section{Conclusion}

The analysis conducted on the South African governmental discourse on IKS revealed a much more complex relationship with ICT in the context of development than is often assumed. Most importantly, it highlights the way that technology is perceived as neither neutral nor a development imperative in and of itself, but rather as something to be selectively utilised, an attitude that has been called 'selective exclusion'. While the approach being advocated by the government representatives in relation to IKS is socio-centric with a heavy emphasis on local knowledge and capabilities, a number of queries regarding its viability and validity remain. The extent to which a 'selective exclusionary' approach is sustainable in an increasingly globalised world and whether it really has practical 
implications in terms of the diffusion of technology also remains an open question.

In relation to the digital divide debate, however, the concept of 'selective exclusion' offers a number of insights. It challenges the simplistic designation of 'have-nots', questioning its position as the negative counterpart to the 'haves', replacing this with an added appreciation for the agency of people who are often treated as passive in the face of externally managed development initiatives. In a similar vein, the rise of IKS, regardless of its practical application or longevity as a fashionable concept, is significant even if its only contribution to the ICT for development discourse is to challenge the notion of information poverty, decoupling information from knowledge. In much the same way that ICT is perceived in the South African governmental discourse on IKS, as both a threat and an opportunity, the recognition that technology is not disseminated in an apolitical historically impartial vacuum is both a challenge and an opportunity for those involved in ICT for development.

The study was limited in scope and a number of questions need to be asked about how representative the governmental discourse is in relation to different groups of people in South Africa. The political implications and context of IKS was only discussed in brief and would benefit greatly both from further detailed empirical research on actual IKS implementations as well as extending the analysis to other African countries.

\section{References}

Adam, R. 2005. Address by the director-general of the Department of Science and Technology of the Republic of South Africa, Dr. Rob Adam at "The international dimension of the Europe of knowledge: A common interest to Europe and to the world" conference, Brussels, Belgium, Thursday 6 October 2005. [Online]. Available WWW: http://www.esastap.org.za/esastap/pdfs/eraconf_adam_oct2005.pdf (Accessed 11 May 2009).

Appadurai, A. 1990. Disjuncture and difference in the global cultural economy. In: Featherstone, M. Global Culture. London: Sage.

Augusto, G. 2008. Digitizing IKS: epistemic complexity, datadiversity and cognitive justice. The International Information and Library Review 40:211-218.

Bridges, 2001. Spanning the digital divide: understanding the tackling the issues. Cape Town: Bridges.

Briggs, J. 2005. The use of indigenous knowledge in development: problems and challenges. Progress in Development Studies 5(2):99-114.

Briggs, J. and Sharp, J. 2004. Indigenous knowledges and development: a postcolonial caution. Third World Quarterly 25(4):661-676.

Burkett, I. 2000. Beyond the 'information rich and poor': futures understandings of inequality in globalising informational economies. Futures 32:679-694.

Chikonzo, A. 2006. The potential of information and communication technologies in collecting, preserving and disseminating indigenous knowledge in Africa. The International Information and Library Review 38:132-138.

Couldry, N. 2003. Digital divide or discursive design? On the emerging ethics of information space. Ethics and Information Technology 5:89-97. 
Cushman, M. and Klecun, E. 2005. How (can) non-users perceive usefulness: bringing in the digitally excluded. Penceil Paper 7. LSE: The Department of Information Systems.

Dasgupta, S., Lall, S. and Wheeler, D. 2005. Policy reform, economic growth and the digital divide. Oxford Development Studies 3(2):229-243.

DiMaggio, P. and Hargittai, E. 2001. From the 'digital divide' to 'digital inequality': Studying Internet use as penetration increases. Princeton University Center for Arts and Cultural Policy Studies, Working Paper Series number 15.

Du Toit, C. 2005. The environmental integrity of African indigenous knowledge systems: probing the roots of african rationality. Indilinga - African Journal of Indigenous Knowledge Systems 4(1):55-73.

Fischer, M.D. 2005. Culture and indigenous knowledge systems: emergent order and the internal regulation of shared symbolic systems. Cybernetics and systems: an International Journal 36:735-752.

Green, L. 2007. The Indigenous Knowledge Systems Policy of 2004: challenges for South African universities. Social Dynamics 33(1):130-154.

Green, L. 2008. Anthropologies of knowledge and South Africa's Indigenous Knowledge Systems Policy. Anthropology Southern Africa 31(1\&2):48-57.

Gunkel, D.J. 2003. Second thoughts: toward a critique of the digital divide. New media \& society 5(4):499-522.

Gurstein, M. 2003. Effective use: a community informatics strategy beyond the digital divide. First Monday 8(12).

Hangana, N. 2007. Speech by Deputy Minister for Provincial and Local Government at the Human Rights and Indigenous Knowledge System Conference at the Sammy Marks Convention Centre, Pretoria, 23 March 2007. [Online] Available WWW:

http://www.info.gov.za/speeches/2007/07101916151005.htm. (Accessed 29 January 2009).

Heeks, R. 2002. i-Development and e-development: special issue on ICTs and development. Journal of International Development 14:1-11.

Higgs, P. 2005. In defence of local knowledge: a theoretical reflection. Indilinga - African Journal of Indigenous Knowledge Systems 5(1):1-11.

Hughes J. and Jones, S. 2003 Reflections on the use of grounded theory in interpretive information systems research. In: Ciborra, C.U., Mercurio, R., de Marco, M., Martinez, M. and Carignani, A. (eds.). Proceedings of the Eleventh European Conference on Information Systems , 833-845, Naples, Italy.

Kargbo, J.A. 2005. Managing indigenous knowledge: what role for public librarians in Sierra Leone? The International Information and Library Review 37:199-207.

Kvasny, L. and Truex, D. 2001. Defining away the digital divide: a content analysis on institutional influences on popular representations of technology. In: Russo, N.L., Fitzgerald, B. and DeGross, J.L. (eds.). Proceedings of the IFIP TC8/WG8.2 Conference on Realigning Research and Practice in Information Systems development: The social and Organizational Perspective. Boston: Kluwer Academic Publishers. 
Makhaya, G. and Roberts, S. 2003. Telecommunications in developing countries: reflections from the South African experience. Telecommunications Policy 27:41-59.

Mangena, M. 2004. Speech presented at the dinner of the Southern African development conference (SADC) workshop on indigenous knowledge. [Online]. Available WWW: http://www.info.gov.za/speeches/2004/04062109451001.htm (Accessed 22 November 2006).

Mangena, M. 2006. Opening speech for the 2006 TCI conference on indigenous knowledge systems. [Online]. Available WWW:

http://www.info.gov.za/speeches/2006/06080212451001.htm (Accessed 22 November 2006).

Mangena, M. 2007a. Budget vote speech by the Minister of Science and Technology, honourable Mopsibudi Mangena, Parliament, Cape Town. [Online]. Available WWW: http://www.info.gov.za/speeches/2007/07052516451001.htm (Accessed 29 January 2009).

Mangena, M. 2007b. Keynote address to the second Southern African Development Community (SADC) workshop on indigenous knowledge systems Livingstone, Zambia. [Online]. Available WWW: http://www.info.gov.za/speeches/2007/07032811151001.htm (Accessed 29 January 2009).

Mangena, M. 2008. Address by Minister Mosibudi Mangena at the induction of the IKS Advisory Committee. [Online]. Available WWW: http://www.dst.gov.za/mediaroom/speeches/ (Accessed 5 February 2009).

Mansell, R. 2001. Digital opportunities and the missing link for developing countries. Oxford Review of Economic Policy 17(2):282-294.

Mehta, S. and Kalra, M. 2006. Information and communication technologies: a bridge for social equity and sustainable development in India. The International Information \& Library Review 38:147-160.

Murdock, G. and Golding, P. 2004. Dismantling the digital divide: rethinking the dynamics of participation and exclusion. In: Calabrese, A. and Sparks, C. (eds.). Toward a political economy of culture: capitalism and communication in the twenty-first century. Lanham, M.D: Rowman and Littlefield.

Nassimbeni, M. 1990. Poverty and development in South Africa and the role of libraries. Journal of Librarianship 22(3):161-170.

National Research Foundation. 2006. Indigenous knowledge systems. [Online]. Available WWW: http://www.nrf.ac.za/focusareas/iks/ (Accessed 6 November 2006).

NEPAD 2001. The new partnership for Africa's development. [Online]. Available WWW: http://www.nepad.org/2005/files/home.php (Accessed 22 November 2006).

Ngubane, B. 2001. Speech presented at the annual general meeting of the international federation of reproduction rights organisations. [Online]. Available http://www.info.gov.za/speeches/2001/011018346p1003.htm (Accessed 22 November 2006).

Ngubane, B. 2003. Speech presented at the signing of a benefit sharing agreement between the CSIR and the San people. [Online]. Available WWW:

http://www.info.gov.za/speeches/2003/03032410461009.htm (Accessed 9 September 2007).

Ngulube, P. and Lwoga, E. 2007. Knowledge management models and their utility to the 
effective management and integration of indigenous knowledge with other knowledge systems. Indilinga - African Journal of Indigenous Knowledge Systems 6(2):117-131.

Orlikowski, W.J. 2000. Using technology and constituting structures: a practice lens for studying technology in organizations. Organization Science Quarterly 11(4):404-428.

Reck, J. and Wood, B. 2003. What works: Vodacom's community services phone shops; providing telecommunications to poor communities in South Africa. What Works Digital Dividend, Michigan Business School.

Roode, D., Speight, H., Pollock, M. and Webber, R. 2004. It's not the digital divide - it's the socio-techno divide! In: Leino, T., Saarinen, T. and Klein, S. (eds.) Proceedings of the Twelfth European Conference on Information Systems, Turku School of Economics and Business Administration, Turku, Finland.

Postma, L. 2001. A theoretical argumentation and evaluation of South African learners; orientation towards and perceptions of the empowering use of information. New media \& society $3(3): 313-326$.

Schech, S. 2002. Wired for change: the links between ICTs and development discourses. Journal of International Development 14:13-23.

Sen, B. 2005. Indigenous knowledge for development: bringing research and practice together. The International Information and Library Review 37:375-382.

Sen, B. and Khashmelmous, N.A. 2006. Incorporating indigenous knowledge materials. Efforts at Elhafeed Library, Ahfad University, Sudan: a preliminary study. The International Information \& Library Review 38:117-122.

Soete, L. 1985. International diffusion of technology, industrial development and technological leapfrogging. World Development 13(3):409-422.

Sonjica, B.P. 2003. Speech presented at the science and education training week gala dinner, Mafikeng, South Africa. [Online]. Available WWW:

http://www.info.gov.za/speeches/2003/03052214461001.htm . (Accessed 22 November 2006).

South Africa. Department of Science and Technology. 2004. Indigenous knowledge systems. Pretoria: Department of Science and Technology.

South African Government. 2007. South Africa Government online. [Online]. Available WWW: http://www.gov.za/ (Accessed 20 March 2007).

South African Government. 2008. Department of Science and Technology (DST) announces plans to bolster indigenous knowledge systems (IKS). [online]. Available WWW:

http://www.info.gov.za/ (Accessed 29 January 2009)

Stewart, C.M., Gil-Egui, G., Tian, Y. and Innes Pileggi, M. 2006. Framing the digital divide: a comparison of US and EU policy approaches. New media \& society 8(5):731-751.

Strauss, A. and Corbin, J. 1998. Basics of qualitative research. London: Sage.

Tella, R.D. 2007. Towards promotion and dissemination of indigenous knowledge: a case of NIRD. The International Information and Library Review 39:185-193. 
Tjiek, L.T. 2006. Desa informasi: the role of digital libraries in the preservation and dissemination of indigenous knowledge. The International Information and Library Review 38:123-131.

UNDP. 2000. South Africa: transformation for human development 2000. Pretoria, South Africa, United Nations Development Programme.

UNDP. 2004. Human development index. United Nations Development Programme.

Van Dijk, J. 2005. From digital divide to social opportunities. Proceedings of 2 nd International Conference for Bridging the Digital Divide, December 2005, Seoul, Korea.

Van Dijk, J. and Hacker, K. 2003. The digital divide as a complex and dynamic phenomenon. Information Society 19(4):315-326.

Vodafone. 2005. Africa: the impact of mobile phones. The Vodafone Policy Papers Series, Vodafone.

Wallner, F. 2005. Indigenous knowledge and western science: contradiction or cooperation. Indilinga - African Journal of Indigenous Knowledge Systems 4(1):46-54.

Warschauer, M. 2002. Reconceptualising the digital divide. First Monday 7(7).

Warschauer, M. 2003. Dissecting the 'digital divide': a case study in Egypt. The Information Society 19:297-304.

Watson, A. and Huntington, O.B. 2008. They're here - I can feel them: the epistemic spaces of indigenous and western knowledges. Social and Cultural Geography 9(3):257-281.

Wejnert, B. 2002. Integrating models of diffusion of innovations: a conceptual framework. Annual Review of Sociology 28:297-326.

Wilson, M. 2002. Understanding the international ICT and development discourse: assumptions and implications. The Southern African Journal of Information and Communication 3(3).

World Bank. 1998. Indigenous knowledge for development: a framework for development, knowledge and learning centre. Africa Region, World Bank. [Online]. Available WWW: http://www.worldbank.org/afr/ik/ikrept.pdf (Accessed 20 March 2007).

\section{Appendix A: List of speeches analysed}

\begin{tabular}{|c|c|c|}
\hline Speaker & Occasion & Audience \\
\hline $\begin{array}{l}\text { B. Ngubane, } \\
\text { Minister of Arts, } \\
\text { Culture, Science } \\
\text { and Technology } \\
\text { (Ngubane 2001) }\end{array}$ & $\begin{array}{l}2001 \text { Annual General } \\
\text { Meeting of the } \\
\text { International } \\
\text { Federation of } \\
\text { Reproduction Rights } \\
\text { Organisations }\end{array}$ & $\begin{array}{l}\text { Representatives } \\
\text { International } \\
\text { Federation of } \\
\text { Reproduction Rights } \\
\text { Organisations }\end{array}$ \\
\hline $\begin{array}{l}\text { B.P. Sonjica, } \\
\text { Deputy Minister of } \\
\text { Arts, Culture, } \\
\text { Science and }\end{array}$ & $\begin{array}{l}2003 \text { Science and } \\
\text { Education Training } \\
\text { Week Gala Dinner; } \\
\text { Mafikeng, South }\end{array}$ & $\begin{array}{l}\text { Mainly dignitaries } \\
\text { from the North- } \\
\text { West Province, } \\
\text { South Africa }\end{array}$ \\
\hline
\end{tabular}




\begin{tabular}{|c|c|c|}
\hline \begin{tabular}{|l} 
Technology \\
(Sonjica 2003)
\end{tabular} & Africa & \\
\hline $\begin{array}{l}\text { B. Ngubane, } \\
\text { Minister of Arts, } \\
\text { Culture, Science } \\
\text { and Technology } \\
\text { (Ngubane 2003) }\end{array}$ & $\begin{array}{l}2003 \text { Signing of a } \\
\text { benefit sharing } \\
\text { agreement between } \\
\text { the CSIR and the San } \\
\text { people. }\end{array}$ & $\begin{array}{l}\text { San representatives } \\
\text { CSIR } \\
\text { representatives } \\
\text { Media }\end{array}$ \\
\hline $\begin{array}{l}\text { M. Mangena, } \\
\text { Minister of Science } \\
\text { and Technology } \\
\text { (Mangena 2004) }\end{array}$ & $\begin{array}{l}2004 \text { Dinner of the } \\
\text { Southern African } \\
\text { Developmental } \\
\text { Conference (SADC) } \\
\text { Workshop on } \\
\text { Indigenous } \\
\text { Knowledge }\end{array}$ & $\begin{array}{l}\text { Representatives of } \\
\text { SADC countries } \\
\text { attending the SADC } \\
\text { workshop. }\end{array}$ \\
\hline \begin{tabular}{|l} 
Dr Rob Adam, \\
Director-General \\
of Science and \\
Technology (Adam \\
$2005)$
\end{tabular} & $\begin{array}{l}2005 \text { International } \\
\text { Dimension of the } \\
\text { Europe of } \\
\text { Knowledge } \\
\text { Conference in } \\
\text { Brussels }\end{array}$ & $\begin{array}{l}\text { Conference } \\
\text { delegates. }\end{array}$ \\
\hline $\begin{array}{l}\text { M. Mangena, } \\
\text { Minister of Science } \\
\text { and Technology } \\
\text { (Mangena 2006) }\end{array}$ & $\begin{array}{l}\text { Opening speech for } \\
\text { the } 2006 \text { TCI } \\
\text { Conference on } \\
\text { Indigenous } \\
\text { Knowledge Systems }\end{array}$ & $\begin{array}{l}\text { Experts, scientists, } \\
\text { holders and } \\
\text { practitioners of IKS } \\
\text { discipline. }\end{array}$ \\
\hline \begin{tabular}{|l|} 
N. Hangana, \\
Deputy Minister \\
for Provincial and \\
Local Government \\
(Hangana 2007) \\
\end{tabular} & $\begin{array}{l}\text { Speech at the Human } \\
\text { Rights and } \\
\text { Indigenous } \\
\text { Knowledge System } \\
\text { Conference }\end{array}$ & $\begin{array}{l}\text { Experts, scientists, } \\
\text { holders and } \\
\text { practitioners of IKS } \\
\text { discipline. }\end{array}$ \\
\hline $\begin{array}{l}\text { M. Mangena, } \\
\text { Minister of Science } \\
\text { and Technology } \\
\text { (Mangena 2007a) }\end{array}$ & $\begin{array}{l}\text { Budget vote speech, } \\
\text { Parliament, Cape } \\
\text { Town }\end{array}$ & $\begin{array}{l}\text { Members of } \\
\text { parliament }\end{array}$ \\
\hline $\begin{array}{l}\text { M. Mangena, } \\
\text { Minister of Science } \\
\text { and Technology } \\
(\text { Mangena 2007b) }\end{array}$ & $\begin{array}{l}\text { Keynote address to } \\
\text { the second Southern } \\
\text { African Development } \\
\text { Community (SADC) } \\
\text { workshop on } \\
\text { indigenous } \\
\text { knowledge systems } \\
\text { Livingstone, Zambia }\end{array}$ & $\begin{array}{l}\text { Representatives of } \\
\text { SADC countries } \\
\text { attending the SADC } \\
\text { workshop. }\end{array}$ \\
\hline $\begin{array}{l}\text { M. Mangena, } \\
\text { Minister of Science } \\
\text { and Technology } \\
\text { (Mangena 2008) }\end{array}$ & $\begin{array}{l}\text { Remarks at the } \\
\text { launch of the } \\
\text { Knowledge for } \\
\text { Africa's } \\
\text { Development Book, } \\
\text { Pretoria }\end{array}$ & $\begin{array}{l}\text { Finnish ambassador, } \\
\text { experts, scientists, } \\
\text { holders and } \\
\text { practitioners of IKS } \\
\text { discipline. }\end{array}$ \\
\hline $\begin{array}{l}\text { M. Mangena, } \\
\text { Minister of Science } \\
\text { and Technology }\end{array}$ & $\begin{array}{l}\text { Address at the } \\
\text { Induction of the IKS } \\
\text { Advisory Committee }\end{array}$ & $\begin{array}{l}\text { Director General, } \\
\text { Members of the } \\
\text { Advisory }\end{array}$ \\
\hline
\end{tabular}




\begin{tabular}{|l|l|} 
(Mangena 2008) & $\begin{array}{l}\text { committee, elders, } \\
\text { practitioners. }\end{array}$ \\
\hline
\end{tabular}

ISSN 1560-683X

Published by InterWord Communications for Department of Information and Knowledge Management, University of Johannesburg 